Article

\title{
Incentives to Open Access: Perspectives of Health Science Researchers
}

\author{
Carmen López-Vergara ${ }^{1, *}$, Pilar Flores Asenjo ${ }^{1}$ (i) and Alfonso Rosa-García ${ }^{2}$ (i) \\ 1 Departamento Ciencias Sociales, Jurídicas y de la Empresa, Universidad Católica San Antonio de Murcia, \\ Av. De los Jerónimos, 135, 30107 Guadalupe, Murcia, Spain; pflores@ucam.edu \\ 2 Departamento de Fundamentos del Análisis Económico, Universidad de Murcia, Campus de Espinardo, \\ Edificio n 2, 30100 Murcia, Spain; alfonso.rosa@um.es \\ * Correspondence: clopez12@alu.ucam.edu
}

Received: 20 April 2020; Accepted: 25 May 2020; Published: 28 May 2020

check for updates

\begin{abstract}
Technological development has transformed academic publication over the past two decades and new publication models, especially Open Access, have captured an important part of the publishing market, traditionally dominated by the Subscription publication model. Although Health Sciences have been one of the leading fields promoting Open Access, the perspectives of Health Science researchers on the benefits and possibilities of Open Access remain an open question. The present study sought to unveil the perspective of researchers on scientific publication decisions, in terms of the Subscription and Open Access publication model, Gold Road. With this aim, we surveyed Spanish researchers in Health Sciences. Our findings show that the value of publishing in Open Access journals increases as the experience of the researcher increases and the less she/he values the impact factor. Moreover, visibility and dissemination of the results are the main determinants of publication when choosing an Open Access journal as the first option. According to the response of the researchers, the reduction of fees and the increase in financing are important economic incentive measures to promote the Open Access publication model. It is widely accepted that the volume of Open Access publications will increase in the future.
\end{abstract}

Keywords: determinants of publication; health sciences; open access; scientific publication

\section{Introduction}

Open Access is the free online availability of scientific research content for reading, downloading, copying, distributing, and printing texts. The only restriction is the recognition of copyrights and intellectual property of the authors of the works, as stated by the Budapest Open Access Initiative (2002), as endorsed by the Bethesda Declaration (2003) and the Berlin Declaration (2003). From these three initiatives, the development of the Open Access movement has been positive and enormously important for science [1], and it has provided significant economic benefits to society [2]. However, despite the changes observed in scientific publication and the increase in Open Access publications [3-5], its use is not as high as predicted. For instance, the objectives set in the $7^{\text {th }}$ Framework Programme: Horizon 2020 [6] regarding the percentage of Open Access publications have not been fully attained, especially for research financed by European funds. It implies the need for a definitive boost to the publication model.

Researchers have two Open Access publication channels, Gold Road, for publications in Open Access scientific journals, and Green Road, which allows self-archiving in the institutional Open Access repositories. It is possible to deposit research papers in the institutional Open Access repositories once the article has been accepted by a Subscription journal, despite the journal's embargo period. This option is valid as long as it is specified in the contract or agreement made with the journal. 
To know the conditions of deposits subject to each journal, one can consult two databases, Dulcinea, for searching within journals in Spanish, and Sherpa/Romeo, for journals in other languages.

Thus, if researchers decide to publish in scientific journals, the main publication models are, firstly, traditional Subscription journals, where researchers try to select a scientifically recognized journal or with a high impact factor, and secondly, Open Access journals, characterized mainly by their high visibility and dissemination [7], an aspect that can increase the presence of the author's work in digital media. In this context, the researchers' perspective on scientific publication is particularly relevant, considering the two publication models. Researchers assume a double role: on the one hand, they are consumers of information and, on the other hand, authors of content. In the latter case, the researcher faces the dilemma of choosing a scientific journal, where to publish the results of his/her work, and the most appropriate publication model to achieve his/her objectives [8,9]. In the development of new strategies, it is therefore fundamental to know the determinants of Open Access publication, the opinion of the author as to the available information on the model of publication, and their forecast about the future of Open Access.

The most prominent publishers offer different publication channels $[9,10]$ : Subscription journals, to which libraries or research centres usually pay subscription fees; and full Open Access journals, where publication fees can be supported by the author [11]. Moreover, there are Subscription journals that allow researchers to publish in Open Access. They are called hybrid journals. Authors who publish their articles in Open Access have to pay publication fees. However, there are no subscription fees for these articles. The Open Access publication fees, Article Processing Charge (APC), are higher in hybrid journals than in full Open Access journals [3], and payment seems to be influenced by disciplinary self-identification [12]. Additionally, in the transformation of Subscription to Open Access publications, the publishers have expanded the publication services offered to the researcher $[3,13]$ and have modified the embargo periods [14,15]. Although there are some journals which have converted from Open Access to traditional Subscription, there is an increasing trend towards Open Access [16]. Publishers such as MDPI (1996), Biomed Central (2000), or Public Library of Science (2003) are pioneers.

The search for a higher impact factor [9,11], the total costs of publication [15], and the quality of the contents [9] are some barriers that have impeded the achievement of the objectives for this decade. Review of the main databases and studies carried out during the last decade show differences in the percentage of Open Access publications, depending on the discipline considered $[8,17,18]$ or country of origin [18]. Specifically, in the area of health sciences, the need for greater internationalization of publications and social interest in research results [19] give it a prominent place within Open Access publications. Moreover, Open Access facilitates the transformation of research into practice [20].

The present study seeks to explore the determinants of Open Access publications, Gold Road, in the area of Health Science, through a survey conducted among medical researchers in Spain. The results obtained indicate that the experience of researchers in Open Access publication, as well as the impact of the journals, their visibility, and dissemination in the Open Access journals, are relevant to the evaluation of the model. It also evaluates the researchers' perspective about economic incentive measures aimed at promoting the publication model.

In the next section, previous surveys on researchers' perspectives of Open Access are discussed. Next, a series of hypotheses to be tested are proposed and the research methodology is explained. Finally, the results and their discussion are presented.

\section{Literature Review}

The first studies exploring the main determinants of Open Access publication, such as that [carried out internationally by the European Commission [21] or in Europe within the 7th Framework Programme [22], found important differences among disciplines and the country of origin. These results are supported by subsequent studies carried out in Germany [17], in Italy [23], and other European countries [18]. The reasons that may explain the results refer to the researchers' publication culture, the Open Access incentive policies, or the regulations applied in each country. 
With reference to the Open Access determinants, knowledge of the model and experience in Open Access publication are relevant aspects in choosing the Open Access journal as the first option $[17,18]$. Researchers' publication decisions are based on personal opinion of the publication model and academic recognition. This opinion is supported by other studies, where the researchers' experience in Open Access publishing is shown as one of the main determinants for choosing the Open Access publication model $[7,22]$.

The study carried out by the University of Eastern Piedmont [24] indicates that publication decisions are mainly influenced by the social norms of each institution. Despite showing a positive relationship between the researcher's status and the knowledge of the Open Access publication model, according to this study, familiarity with the Open Access publication model is insufficient to influence publication decisions [23].

In the specific case of Health Sciences, the study by Eger [17] in Germany shows that the disciplines of Biology and Health Sciences have the highest percentage of Open Access publications, where 54 percent of researchers have sometimes published using this model. Similar results were obtained in Greece, Italy, and Turkey [18], where the highest percentage of researchers, who have sometimes published in Open Access, is in the area of Health Sciences. One of the main reasons for nonpublication in Open Access, explained by the researchers, is the high cost of publishing in Open Access journals. These results are supported by the study carried out in Italy by Migheli and Ramello [24].

In Spain, the researchers' publication decisions have been analyzed by the European Commission [22] or Eger's study [18]. The results highlight the higher probability of Open Access publishing in Spain than in Germany and other European countries. More recently, Ruiz-Pérez [25] carried out a survey directed at Spanish researchers, finding differences among disciplines and age groups. The results show that almost 70 percent of researchers had sometimes published in Open Access. In terms of disciplines, medicine stands out, where 89 percent of researchers have knowledge of the Open Access publication model.

Despite the great interest of Health Science in the Open Access publication model, previous studies have not specifically addressed the determinants and perspectives in this particular area, except as part of more general studies. Moreover, the relevance of the different economic incentives has not been studied. The present study fills this gap.

\section{Materials and Methods}

\subsection{Hypothesis}

Knowledge of the Open Access publication model and experience in publishing using this model can be decisive in evaluating it and choosing an Open Access journal as the first option $[17,18]$. Despite the fact that the seniority of the researchers does not mean greater knowledge of the model of publication [17], the results show that the higher the status of the researcher, the higher the experience in the Open Access publication and the assessment of the model. This association is observed in disciplines such as medicine [24]. This raises the first hypothesis about researchers in Spain:

Hypothesis 1 (H1). The higher the research experience of the medical researcher, the higher the assessment of the Open Access publication model.

Open Access publishing has undergone significant evolution in the last two decades. However, there are different barriers that have prevented a definitive boost to the model. Among the most prominent are the publication costs $[3,26,27]$. Economic incentive measures, aimed at reducing the cost of Open Access publishing and coordinated by different interest groups, can help increase the number of Open Access publications. The economic viability of these incentive measures is justified by previous studies $[9,15,28]$. It leads to our second hypothesis: 
Hypothesis 2 (H2). Medical researchers consider that lower publication fees could boost the Open Access publication model.

One economic incentive measure is to increase funding for Open Access publishing [3,5,26,27], which needs the key participation of funding institutions [3,15]. Increased funding for Open Access publication can be accomplished through two main ways. The first is financing of the publication by the research centre or by an external institution. The second could be the allocation of a part of research budgets to an Open Access publication. Our third hypothesis states its relevance:

Hypothesis 3 (H3). Medical researchers consider that an increase in funding is an adequate economic incentive measure to promote the Open Access publication model

The increase in digital content available in Open Access, the consideration of the number of downloads of scientific articles, and the growing importance of academic and research social networks have changed the perspective of researchers on scientific publication. The demand for greater visibility and dissemination of content [7] and the reduction of embargo periods [15] may be decisive in the increase in Open Access publications. The authors who have experienced this are possibly more likely to expect that the advantages of Open Access will push its development. This leads to our fourth hypothesis:

Hypothesis 4 (H4). The higher the valuation of the experience in open access publishing, the higher the expected increase of Open Access publications volume.

Finally, according to the results obtained in previous studies, the fundamental factor when choosing an Open Access journal as the first option is the visibility and dissemination of content $[7,14,23]$. This aspect differentiates Open Access publications from subscription publications, in which the impact factor is more highly valued $[9,11,29]$. This motivates our fifth hypothesis:

Hypothesis $\mathbf{5}$ (H5). The main reason for Open Access publication is visibility and dissemination.

\subsection{Research Setting}

The main objective is to unveil the perspective of health science researchers on decisions about scientific publication. For this purpose, a survey was designed and sent to Spanish researchers belonging to Doctorate Schools of Medicine, included in the Registry of Universities, Centres and Degrees (RUCT) of the Ministry of Education, Culture and Sport. Questionnaires were drawn up using Google Drive forms. The data collection was from the information published, gathering the contact information of researchers through the web pages of each Doctoral School.

As a previous step to sending the questionnaires, the survey was reviewed by experts in the subject. The final questionnaire was sent to 3374 researchers belonging to 53 universities. The data were collected in three phases, developed during the second half of 2018. The first started on October 3 , the second on November 4, and the third on November 26.

\subsection{Survey Description}

The questionnaire was divided into four parts (see Appendix A). The first part was designed to test hypothesis $\mathrm{H}_{1}$. For this purpose, information regarding research experience, the percentage of Open Access publications, and the assessment of experience in Open Access publication were collected. The measurement of the first and third questions was carried out using a five-point Likert scale, where 1 gives a minimum or very unfavorable score and 5 is the maximum score or totally favorable. The second part refers to hypothesis $\mathrm{H}_{5}$. It evaluates the selection criteria for the scientific journal, considering the two main models, the sources of information for choosing the journal, and the factors related to the 
selection of Open Access as publication model. The third part refers to the economic incentives in terms of Open Access publication, in reference to hypothesis $\mathrm{H}_{2}$ and $\mathrm{H}_{3}$. The fourth part asks researchers' opinion on the information available about the Open Access model, following hypothesis $\mathrm{H}_{4}$. Finally, researchers could express their opinion and experience in scientific publication via email. Comments received have been added to the survey results in the Discussion and Conclusions section.

\subsection{Statistical Methods}

We assessed the validity of the set of items using the Cronbach's coefficient alpha [30]. We used $5 \%$ as our level of significance and $95 \%$ confidence intervals. We studied the bivariate relations using contingency tables and tested the relations with the Chi-square test for our hypotheses $\mathrm{H}_{1}, \mathrm{H}_{2}, \mathrm{H}_{3}$, and $\mathrm{H}_{5}$. We disentangled the effects of the different variables on the percentage of Open Access publication and on the valuation of the Open Access model with Ordinary Least Square regressions, which allowed us to test our Hypothesis $\mathrm{H}_{4}$. In order to assess how each determinant affects the probability of expecting an increase in the future use of the model, we used a logistic regression, which is best adapted to the probability estimation of a dichotomous variable.

\section{Results}

\subsection{Descriptive Statistics}

The survey was sent to 3374 researchers and 414 responses were received, the response rate was $12.3 \%$. The majority of respondents had more than 6 years of research experience $(97.8 \%)$ and $72.9 \%$ had more than 18 years of research experience. On average, researchers state they have published $22 \%$ (SD $=22.43$ ) of their papers as Open Access. Measured on a five-point Likert scale, where 1 is the lowest score and 5 the highest, researchers' valuation of their experience in Open Access publishing is $3.40(\mathrm{SD}=1.11)$.

With respect to the relevance of the different economic incentives to Open Access publications, $85.8 \%$ and $84.7 \%$ of researchers consider as adequate measures the reduction in publication fees and an increase in funding, respectively. Regarding the main determinants on the selection of a journal as a first option, the impact factor is the most valuated reason, with a mean of 4.59 ( $S D=0.80)$, followed by publication topic (mean $=4.25, \mathrm{SD}=0.89$ ) and publication costs (mean $=3.41, \mathrm{SD}=1.28)$. The rest of the determinants are less relevant (see Table 1 ).

Table 1. Assessment of the selection criteria of a scientific medical journal.

\begin{tabular}{cccc}
\hline Selection Criteria & N & Mean & Standard Deviation (SD) \\
\hline Impact Factor & 364 & 4.59 & 0.80 \\
\hline Publication topic & 364 & 4.25 & 0.89 \\
\hline Cost of publication & 363 & 3.41 & 1.28 \\
\hline Open Access/Subscription & 362 & 2.62 & 1.19 \\
\hline Rejection rate & 360 & 2.39 & 1.08 \\
\hline Periodicity of publications & 361 & 2.26 & 1.13 \\
\hline Number of articles/year & 362 & 2.22 & 1.12 \\
\hline
\end{tabular}

When the decision is restricted to an Open Access journal, dissemination and visibility were the major selection criteria, with a mean of $3.99(\mathrm{SD}=1.16)$, followed by impact factor (mean $=3.86$, $\mathrm{SD}=1.21$ ), academic recognition and, lastly, the cost of publication (see Table 2). 
Table 2. Assessment of the selection criteria of an Open Access medical journal.

\begin{tabular}{cccc}
\hline Selection Criteria & $\mathbf{N}$ & Mean & Standard Deviation (SD) \\
\hline Visibility and dissemination & 353 & 3.99 & 1.16 \\
\hline Impact factor & 356 & 3.86 & 1.21 \\
\hline Academic recognition & 351 & 3.18 & 1.24 \\
\hline Cost of publication & 353 & 2.75 & 1.39 \\
\hline
\end{tabular}

Given the dilemma of choosing between two journals, subscription and Open Access, both with the same topic, academic recognition and cost of publication, if the Subscription journal has an impact factor equal to 1, the medical researcher would prefer to publish in the Open Access journal if it has an impact factor equal to 1.35 ( $\mathrm{SD}=0.47)$. On the other hand, when considering two journals on the same topic, academic recognition and impact factor equal to 1, if the Subscription journal has a publication cost of $€ 2500$, the health science researchers express willingness to pay up to $€ 1619$ ( $\mathrm{SD}=997$, confidence interval 95\%: 1516 to 1721 ).

Finally, 70\% of researchers answered that currently researchers do not have enough information about the Open Access publishing model. In addition, $85 \%$ of researchers responded that the percentage of participation of Open Access publications, in the total volume of publications, will increase in the future.

\subsection{Contingency Table Analysis}

The data obtained in the survey present different types of associations between the qualitative variables. The validity of the set of items, measured by the internal consistency method based on the Cronbach's coefficient alpha [30], obtains an alpha value of 0.71 , allowing the joint analysis of the variables. The study of the association between qualitative variables is based on the following contingency tables:

Hypothesis $\mathrm{H}_{1}$ relates the higher experience to an increase in the assessment of the Open Access publication model; $26.4 \%$ of researchers who have rated the experience in Open Access publishing with the highest score, 5 points, have between 6 and 18 years of research experience, and $73.6 \%$ over 18 years (see Table 3). This positive association between the variables is not significant (Chi-square test: $\left.\mathrm{X}^{2}(12)=15.075, p=0.237\right)$.

Table 3. Assessment of experience in Open Access publishing (1 to 5) according to years of experience.

\begin{tabular}{ccccccc}
\hline & $\mathbf{1}$ & $\mathbf{2}$ & $\mathbf{3}$ & $\mathbf{4}$ & $\mathbf{5}$ & Total \\
\hline <6 years & 0 & 3 & 1 & 4 & 0 & 8 \\
6-18 years & 5 & 5 & 33 & 26 & 14 & 83 \\
>18 years & 23 & 26 & 78 & 92 & 39 & 258 \\
TOTAL & 28 & 34 & 112 & 122 & 53 & 349 \\
\hline
\end{tabular}

Result 1: The higher the research experience, the higher the relative assessment of Open Access publication by medical researchers. This relationship is not statistically significant, so hypothesis $\mathrm{H}_{1}$ cannot be accepted.

Hypothesis $\mathrm{H}_{2}$ considers the reduction of fees of publication as an adequate measure of economic incentive to publish in Open Access; $94.3 \%$ of the researchers who have rated the publication cost with a 5 think that the reduction of fees may be a measure of economic incentive, for a $95 \%$ confidence level (see Table 4) (Chi-square test: $\left.X^{2}(4)=35.525, p<0.001\right)$. 
Table 4. Relevance of the cost of publication in choosing the journal (1 to 5), compared with the reduction of Open Access fees as an incentive measure (YES/NO).

\begin{tabular}{ccccccc}
\hline & $\mathbf{1}$ & $\mathbf{2}$ & $\mathbf{3}$ & $\mathbf{4}$ & $\mathbf{5}$ & Total \\
\hline NO & 16 & 11 & 13 & 7 & 5 & 52 \\
YES & 27 & 25 & 86 & 91 & 82 & 311 \\
TOTAL & 43 & 36 & 99 & 98 & 87 & 363 \\
\hline
\end{tabular}

Note that $90.2 \%$ of researchers who gave a 5 point assessment of the cost of publication, as a determining criterion in the choice of the Open Access journal, believe that the reduction in fees may be a measure of economic incentive to Open Access publication, for a 95\% confidence level (see Table 5) (Chi-square test: $\left.\mathrm{X}^{2}(4)=11.131, p=0.025\right)$.

Table 5. Relevance of the cost of publication in choosing the Open Access journal (1 to 5), compared with the reduction of Open Access fees as an incentive measure (YES/NO).

\begin{tabular}{ccccccc}
\hline & $\mathbf{1}$ & $\mathbf{2}$ & $\mathbf{3}$ & $\mathbf{4}$ & $\mathbf{5}$ & Total \\
\hline NO & 20 & 10 & 12 & 2 & 5 & 49 \\
YES & 74 & 53 & 71 & 60 & 46 & 304 \\
TOTAL & 94 & 63 & 83 & 62 & 51 & 353 \\
\hline
\end{tabular}

Result 2: The more significant the cost of publication, the more relevant the reduction in fees considered as an economic incentive measure to promote the Open Access publication model. This relationship is statistically significant for a 99 percent confidence level, so hypothesis $\mathrm{H}_{2}$ is accepted. Considering the researchers who value most the cost of publication in Open Access journals, the relationship is statistically significant for a $95 \%$ confidence level $(p=0.025)$. In this case, hypothesis $\mathrm{H}_{2}$ is also accepted.

Hypothesis $\mathrm{H}_{3}$ relates to the increase in funding for publication as an economic incentive measure to promote the Open Access publication model (see Table 6). Note that $93.1 \%$ of researchers, who rate the publication cost with a 5, without specifying the publication model, believe that an increase in the funding may be a measure of economic incentive to Open Access publishing, for a $95 \%$ confidence level (Chi-square test: $\left.\mathrm{X}^{2}(4)=27.212, p<0.001\right)$.

Table 6. Relevance of the cost of publication in the selection of the journal (1 to 5) compared with the increase in funding, as an initiative measure, in Open Access (YES/NO).

\begin{tabular}{ccccccc}
\hline & $\mathbf{1}$ & $\mathbf{2}$ & $\mathbf{3}$ & $\mathbf{4}$ & $\mathbf{5}$ & Total \\
\hline NO & 16 & 9 & 17 & 8 & 6 & 56 \\
YES & 27 & 27 & 82 & 90 & 81 & 307 \\
TOTAL & 43 & 36 & 99 & 98 & 87 & 363 \\
\hline
\end{tabular}

Note that $94.1 \%$ of researchers, who value the cost of publication with a 5 , as the main criterion for choosing the Open Access scientific journal, think that increased funding may be a measure of economic incentive for the model (see Table 7), for a 95\% confidence level (Chi-square test: $\left.X^{2}(4)=15.395, p=0.004\right)$.

Table 7. Relevance of the cost of publication in the selection of the Open Access journal (1 to 5) compared with the increase in funding, as an initiative measure, in Open Access (YES/NO).

\begin{tabular}{ccccccc}
\hline & $\mathbf{1}$ & $\mathbf{2}$ & $\mathbf{3}$ & $\mathbf{4}$ & $\mathbf{5}$ & TOTAL \\
\hline NO & 23 & 9 & 13 & 3 & 3 & 51 \\
YES & 71 & 54 & 70 & 59 & 48 & 302 \\
TOTAL & 94 & 63 & 83 & 62 & 51 & 353 \\
\hline
\end{tabular}


Result 3: Researchers who consider the cost of publication as more relevant also consider that increasing funding can be an adequate measure. This relationship is statistically significant for a $95 \%$ confidence level, so hypothesis $\mathrm{H}_{3}$ is accepted. Considering the researchers who most value the cost of publication in Open Access journals, the relationship is statistically significant for a 95\% confidence level, so hypothesis $\mathrm{H}_{3}$ is accepted again.

Hypothesis $\mathrm{H}_{4}$ analyzes the experience with Open Access and the perspectives on the future of Open Access publications (see Table 8). The relation is once again significant (Chi-square test: $\left.\mathrm{X}^{2}(4)=36.110, p<0.001\right)$.

Table 8. Assessment of the experience in Open Access publishing (1 to 5), against the opinion on the future increase in Open Access publications (YES/NO).

\begin{tabular}{ccccccc}
\hline & $\mathbf{1}$ & $\mathbf{2}$ & $\mathbf{3}$ & $\mathbf{4}$ & $\mathbf{5}$ & Total \\
\hline NO & 12 & 12 & 16 & 9 & 4 & 53 \\
YES & 16 & 22 & 97 & 114 & 50 & 299 \\
TOTAL & 28 & 34 & 113 & 123 & 54 & 352 \\
\hline
\end{tabular}

Considering the selection criteria for Open Access journals, 91.3\% of researchers, who gave a score of 5 for the visibility and dissemination of Open Access scientific journals, believe that, in future, the volume of Open Access publications will increase, for a 95\% confidence level (Chi-square test: $\left.X^{2}(4)=29.215, p<0.001\right)$. Additionally, 68.7\% of researchers, who rated the Open Access model with a 5 as the main selection criterion for the scientific journal, think that researchers do not have enough information about the Open Access publication model, for a 95\% confidence level (Chi-square test: $\left.\mathrm{X}^{2}(4)=13.760, p=0.008\right)$.

Result 4: Researchers who value more highly their experience in Open Access publishing consider that the volume of open access publications will increase. The relationship is statistically significant for a $95 \%$ confidence level, so hypothesis $\mathrm{H}_{4}$ is accepted.

\subsection{Correlates of Publication Model Selection}

Now we shall explore the correlates of why the Open Access publication model is chosen; how Open Access is valued; and the valuation of the future of the Open Access publication model.

Table A1 (see Appendix B) shows the results of the linear regression analysis for the dependent variable "Percentage of Open Access publications." The factors that we consider may explain that the selection of Open Access is related, on the one hand, to the most relevant aspects that explain the selection of Open Access as the first option and, on the other hand, to the aspects that determine, in general, which journal is selected. Regression (1) relates the percentage of Open Access publication of a researcher to the value the researcher considers that impact factor and cost of publication have in order to choose Open Access as a first option for publishing the results. Regression (2) relates the percentage of Open Access publications to the main aspects of publication when considering a journal of any type. Regression (3) combines both aspects together.

The importance of the different factors when choosing an Open Access journal (column 1) do not seem to be related to the use of Open Access, since only the relevance of impact factor is weakly (at $10 \%)$ significant (and it disappears when all variables are considered together, in column 3). The different considerations for choosing a journal in general (column 2) are more related to the percentage of Open Access publications. In particular, there is a negative significant relation between the relevance of costs and Open Access publications (those researchers who consider cost as a more relevant decision variable tend to publish less in Open Access journals). There is also a positive relation that indicates that those researchers who give more relevance to the publication model (if the journal is Open Access or not) tend to publish more in Open Access journals. This relation remains significant when all possible correlates are considered together (column 3). 
Table A2 (see Appendix B) analyzes the factors that correlate with the assessment that the researcher does about her/his experience with Open Access publications. The regression (1) relates this assessment to how the researcher values the different aspects of a journal. The regression (2) relates the evaluation of the experience with the main aspects of Open Access publication. The regression (3) studies all the previous aspects together.

In column (1) in Table A1, we only find a significant relation between the relevance of the publication model and how Open Access is evaluated: researchers who consider the type of publication model to be more relevant when choosing a journal also value their Open Access publishing experience more highly. When we move to the factors that are considered important with respect to Open Access (column 2), we find that only the importance given to higher visibility is related to the assessment of Open Access as a publication model. When all variables are taken together (column 3), impact factor also appears with a significant negative coefficient, indicating that those researchers who value impact factor more tend to evaluate their experience lower in Open Access publications.

Finally, Table A3 (see Appendix B) presents the results of the logistic regression analysis where we estimate the probability of considering that Open Access will increase in the future as a function of a set of different factors. The logistic regression model was used because the answer option for question 11 , asked in the survey, is dichotomous.

Column (1) relates the dependent variable to the evaluation of the experience in Open Access publishing and the cost and impact factor required of the Open Access journals; column (2) values the opinion of the future of Open Access publications, in relation to the main aspects of publication, considering all scientific journals; column (3) relates the future of publications to the main aspects of Open Access publishing; and column (4) considers all those factors together.

Separately, the evaluation of the experience in Open Access publishing and the visibility are very significant $(p<0.01)$. Considering two publication models, the impact factor $(p<0.05)$, the publication model (weakly significant, $p<0.1$ ), and the cost required for Open Access journals (weakly significant, $p<0.1)$ are significant. In the joint analysis, the assessment of Open Access experience $(p$-value $<0.01)$, the impact factor ( $p$-value $<0.05$ ), and the visibility of the Open Access journals (weakly, $p$-value $<0.1$ ) are significant. This implies that those researchers who consider that Open Access will increase in the future are mainly those who value positively their experience in Open Access publication as well as those who give more value to the impact factor in their decisions.

Result 5: The main reason for Open Access publication is visibility and dissemination, ahead of other relevant publication determinants such as the impact factor and the cost of publication. In these cases, hypothesis $\mathrm{H}_{5}$ is accepted.

\section{Limitations and Discussion}

The study carried out had some limitations that should be considered when interpreting the results. The first was the participation rate in the survey, $12.3 \%$. Review of other online reference surveys shows that the participation rate is within the expected values according to the characteristics of the study and the selected sample. The survey carried out at the University of Otago had a participation rate of $15.8 \%$ [8]. The Study of Open Access Publishing, financed by the European Commission in 2011, worldwide, had a participation rate of 3.6\% [21]. However, the results obtained would have a higher value with higher participation rates. Furthermore, the second limitation is the study in a single discipline. Although the results obtained in a single discipline allow us to know more precisely the publication perspective of medical researchers, it is not possible to know if these results can be extrapolated to other disciplines. In fact, the third limitation is the comparison with other studies that include more disciplines and the sample is made up of highly experienced researchers. Although, in this sense, there are precedents in Spain, where surveys have been carried out with a sample made up of highly experienced researchers with high academic status [31].

In our survey, we find that Open Access publication is better valued by researchers with more experience in this type of publication. Therefore, measures aimed at promoting the publication 
model should consider increasing the experience of the model among researchers, as one of its main objectives. Our results indicate that researchers who value the impact factor more tend to evaluate their experience less in Open Access publishing. This result could be generated because the more traditional, high-impact journals usually follow the Subscription publication model, or it may also indicate that the Open Access journals are not adequately attracting those researchers who value the impact factor more when choosing where to publish. Further research is needed in order to clarify this point.

The measures implemented in Europe [22], as part of the 7th Horizon Framework Program 2020, are aimed at the deposit in institutional Open Access repositories of the publications derived from research projects in certain areas selected by the European Commission itself. However, the increase in experience in the Open Access publication model should not only be promoted through the Green Road, it is also necessary to put in place measures aimed at increasing experience through the two publication models, Green Road and Gold Road. Especially, actions are needed for the provision of services and economic incentives, for publications in journals with Article Processing Charges. Additionally, the scientific publication decisions of medical researchers should be taken into account in the agreement established between publishers and research institutions $[3,9,27]$, looking for a more active participation in decisions that directly affect their research activity.

Our results also reveal what economic incentives would be better accepted by researchers, such as reducing publication fees or increasing funding for Open Access publishing, with funds from the same institution or external financing. However, these economic incentives are not sufficient if the total costs of publication are not considered and prices are adapted to these costs $[3,14,28]$. In fact, unjustified increase in prices may affect the funding of research, causing a redistribution of economic resources towards publication that could harm the progress of scientific research. In this way, it is necessary to consider that economic incentive measures need to be accompanied by greater transparency, especially in agreements between research institutions and publishers [9,15].

On the other hand, in choosing the journal selected as the first option, considering the two publication models, the most important determinant is the impact factor [9]; but when the considerations are made with respect to an Open Access journal, the visibility and dissemination of content is the most valued factor. The difference between both models is in the researcher's publication objectives. The search for a higher impact factor may respond to questions of academic promotion, as well as the desire to publish in journals with greater relevance. Visibility and dissemination of research results may be required in rapidly developing research, subject to continuous innovation, also in search of a greater online presence within the scientific community.

In recent years, new publication models have emerged in response to researchers' demand for publications in journals with a high impact factor and broad visibility. One of them is the hybrid model, mentioned earlier in the introduction, where researchers can publish Open Access articles in some high-impact factor Subscription journals. Another is the Platinum Open Access publication model, or Diamond Open Access publication model, with permanent and free access to published scientific works for readers, without publication fees for the authors, who retain copyright of their work and allow it to be shared and reused. The publication costs are completely paid by one or more financing institutions [9].

The data obtained in Spain vary from those previously observed in other European countries in the evaluation of the publication factors. While in these countries, the cost of publication is the main reason for not publishing in Open Access [18]; in Spain, considering the two publication models, the impact factor is the main determinant in the choice of the journal, followed by the publication issue of the journal and, thirdly, the cost of publication. When evaluating only the Open Access publication model, visibility and dissemination are the main determinants in the choice of the journal. This result coincides with that obtained in other countries. These differences can be due to differences in Open Access policies and the publication culture in each research institution [31] or country [32].

Taken together, policies aimed at increasing Open Access publications should take into account the demand for services, from researchers, and the financing needs for publication. Undoubtedly, 
the benefits of Open Access are widely known and accepted by medical researchers. However, the promotion of the model continues to pose legal and technical challenges that will have to be overcome.

Author Contributions: The data collection for this study was carried out by C.L.-V. as part of her thesis in Social Sciences at the Catholic University of Murcia. P.F.A. was director of the doctoral thesis, supervised the data and the article. A.R.-G. was director and tutor of the doctoral thesis, reviewed the data, the article and the fulfillment of the publication requirements. The three participated in the planning of the study and the article. All authors have read and agreed to the published version of the manuscript.

Funding: This research received no external funding.

Acknowledgments: We would like to thank the collaboration of the medical researchers who have participated in the survey, expressing their opinion and experience in the publication in open access. Without your contribution, this study would not have been possible. In addition, we thank the researchers of the Doctoral Programme in Social Sciences at the Catholic University of Murcia for the help provided in the revision of the survey.

Conflicts of Interest: The authors declare no conflict of interest.

\section{Appendix A}

Survey of Medical Researchers (2018).

PART I: “RESEARCHER DATA”

1. How much experience do you have as a researcher?

- Less than 6 years.

- Between 6 and 18 years.

- Over 18 years.

2. Approximately, what percentage of your publications in scientific journals has been in Open Access?

3. How do you value your experience in Open Access publishing? 1 is the minimum score and 5 is the maximum.

\begin{tabular}{lllll}
\hline 1 & 2 & 3 & 4 & 5 \\
\hline
\end{tabular}

PART II: “CHOICE OF THE SCIENTIFIC JOURNAL WHERE TO PUBLISH THE RESULTS OF YOUR RESEARCH"

4. Score the following selection criteria for the scientific journal chosen as the first option. 1 is the minimum score and 5 is the maximum.

\begin{tabular}{cllllll} 
& 1 & 2 & 3 & 4 & 5 \\
\hline Impact factor & & & & & \\
Publication topic & & & & & \\
Publication cost & & & & & \\
Open Access/Subscription & & & & & \\
Number of articles per year & & & & & \\
Periodicity of publications & & & & & \\
Rejection rate & & & & & \\
\hline
\end{tabular}

5. In the choice of scientific journals with topics related to your field of research, what are your main criteria? You can choose more than one option.

- The experience of previous publications.

- Advice from other researchers in the same discipline.

- Research centre recommendation. 
- Search and comparison in relevant databases.

6. Indicate your assessment of some of the main reasons for publication in Open Access scientific journals:

\begin{tabular}{cccccc}
\hline & 1 & 2 & 3 & 4 & 5 \\
\hline Visibility and dissemination & & & & & \\
Impact factor & & & & & \\
Academic recognition & & & & & \\
Publication cost & & & & & \\
\hline
\end{tabular}

PART III: “ECONOMIC INCENTIVE TO OPEN ACCESS PUBLISHING”

Suppose you want to publish the results of your research in a scientific journal. To do so, you have several options in Subscription and Open Access journals, within the same theme and with equal prestige. According to your opinion, answer the following questions:

7. One economic incentive measure is the reduction of publication fees. Do you think this action would boost Open Access publishing?

- YES, I think it would increase the Open Access publication.

- $\mathrm{NO}$, the cost of publication is not the main determinant in the final decision.

8. In your opinion, increased funding for Open Access publishing, can it be an economic incentive for publication?

- YES, I think it would increase the Open Access publication.

- $\mathrm{NO}$, increased funding is not the main determinant in the final decision.

9. Suppose there is a Subscription journal with impact factor IF $=1$, and an Open Access journal with exactly the same theme, publication cost and academic recognition. What minimum impact factor should the Open Access journal have to be chosen as the first option?

\begin{tabular}{lllllllll}
\hline & 0.25 & 0.50 & 0.75 & 1 & 1.25 & 1.50 & 1.75 & 2 \\
\hline Open access & & & & & & & & \\
\hline
\end{tabular}

10. Suppose there is a Subscription journal with a publication cost of $2500 €$, and an Open Access journal with exactly the same theme, impact factor and academic recognition. What cost should the Open Access journal have to be chosen as the first option?

\begin{tabular}{llllllll}
\hline & 0 & 500 & 1.000 & 1.500 & 2.000 & 2.500 & 3.000 \\
\hline Open access & & & & & & & \\
\hline
\end{tabular}

PART IV: "FUTURE OF THE OPEN ACCESS PUBLICATION MODEL"

In the near future, an increase in digital content and the use of new communication technologies is expected. In your opinion, answer the following questions:

11. Regarding the Open Access publication model, do you think the percentage of participation in the total volume of publications will increase?

- YES, it is a logical and inevitable process.

- $\quad \mathrm{NO}$, publications in Subscription journals will dominate the publishing market. 
12. Do you think that researchers currently have enough information about Open Access publishing?

- YES

- $\mathrm{NO}$

\section{Appendix B}

In Table A1, column 1 considers the cost and impact factor required for the Open Access journal to be chosen as the first option. Column 2 considers the determinants of publication without specifying the publication model. Column 3 considers the correlation types. The estimation coefficient is reported for each variable and the standard deviation in parentheses.

Table A1. Determining factors of the percentage of Open Access publications. Regression by Ordinary Least Squared (OLS).

\begin{tabular}{|c|c|c|c|}
\hline & (1) & (2) & (3) \\
\hline \multirow[t]{2}{*}{ Constant } & $27.152 * * *$ & $18.456^{* *}$ & 1.069 \\
\hline & $(3.853)$ & $(8.367)$ & $(9.877)$ \\
\hline \multirow[t]{2}{*}{ Impact factor required of Open Access } & $-4.100 *$ & & -1.078 \\
\hline & $(2.249)$ & & $(2.579)$ \\
\hline \multirow[t]{2}{*}{ Cost required of Open Access } & $2.409 \cdot 10^{-5}$ & & -1.036 \\
\hline & $(0.001)$ & & $(0.001)$ \\
\hline \multirow[t]{2}{*}{ Impact factor } & & -1.139 & -0.769 \\
\hline & & $(1.618)$ & $(1.810)$ \\
\hline \multirow[t]{2}{*}{ Publication subject } & & 1.146 & 0.531 \\
\hline & & $(1.477)$ & $(1.491)$ \\
\hline \multirow[t]{2}{*}{ Cost of publication } & & $-3.223^{* * *}$ & $-2.259 * *$ \\
\hline & & $(0.938)$ & $(1.006)$ \\
\hline \multirow[t]{2}{*}{ Model of publication } & & $7.065^{* * *}$ & $3.825^{* * *}$ \\
\hline & & $(1.120)$ & $(1.244)$ \\
\hline \multirow[t]{2}{*}{ Number of articles/year } & & $-3.673 *$ & -1.243 \\
\hline & & $(2.042)$ & $(2.046)$ \\
\hline \multirow[t]{2}{*}{ Periodicity } & & 1.131 & 0.109 \\
\hline & & $(1.945)$ & (1.950) \\
\hline \multirow[t]{2}{*}{ Rejection rate } & & 0.941 & 0.279 \\
\hline & & (1.182) & (1.178) \\
\hline $\mathrm{R} 2$ & 0.010 & 0.137 & 0.213 \\
\hline $\mathrm{F}$ & 1.705 & 7.514 & 5.857 \\
\hline Sample & 346 & 339 & 318 \\
\hline
\end{tabular}

In Table A2, Column 1 considers the determinants of publication without specifying the publication model. Column 2 considers the determinants of publication in an Open Access journal. Column 3 considers the correlation types. The estimation coefficient is reported for each variable and the standard deviation in parentheses. 
Table A2. Determining factors of the evaluation of the experience in Open Access publishing. Regression by Ordinary Least Squares (OLS).

\begin{tabular}{|c|c|c|c|}
\hline & (1) & (2) & (3) \\
\hline \multirow[t]{2}{*}{ Constant } & $3.027^{* * *}$ & $2.155^{* * *}$ & $5.163^{* * *}$ \\
\hline & $(0.416)$ & $(0.249)$ & $(0.450)$ \\
\hline \multirow[t]{2}{*}{ Impact factor } & -0.053 & & $-2.054 * *$ \\
\hline & $(0.081)$ & & $(0.085)$ \\
\hline \multirow[t]{2}{*}{ Publication subject } & 0.014 & & -0.818 \\
\hline & $(0.072)$ & & $(0.071)$ \\
\hline \multirow[t]{2}{*}{ Cost of publication } & -0.067 & & -0.343 \\
\hline & $(0.047)$ & & $(0.048)$ \\
\hline \multirow[t]{2}{*}{ Model of publication } & $0.325 * * *$ & & $3.449 * * *$ \\
\hline & $(0.054)$ & & $(0.059)$ \\
\hline \multirow[t]{2}{*}{ Number of articles/year } & -0.081 & & -0.748 \\
\hline & $(0.100)$ & & $(0.097)$ \\
\hline \multirow[t]{2}{*}{ Periodicity } & 0.023 & & 0.152 \\
\hline & $(0.096)$ & & $(0.093)$ \\
\hline \multirow[t]{2}{*}{ Rejection rate } & 0.023 & & 0.982 \\
\hline & $(0.058)$ & & $(0.056)$ \\
\hline \multirow[t]{2}{*}{ Visibility Open Access } & & $0.219^{* * *}$ & $3.285^{* * *}$ \\
\hline & & $(0.053)$ & $(0.054)$ \\
\hline \multirow[t]{2}{*}{ Impact factor Open Access } & & 0.072 & $2.484^{* *}$ \\
\hline & & $(0.057)$ & $(0.060)$ \\
\hline \multirow[t]{2}{*}{ Recognition Open Access } & & 0.058 & -0.334 \\
\hline & & $(0.056)$ & $(0.056)$ \\
\hline \multirow[t]{2}{*}{ Cost of publication Open Access } & & -0.033 & -0.278 \\
\hline & & $(0.045)$ & $(0.046)$ \\
\hline $\mathrm{R} 2$ & 0.110 & 0.084 & 0.260 \\
\hline $\mathrm{F}$ & 5.919 & 7.691 & 7.588 \\
\hline Sample & 341 & 341 & 318 \\
\hline
\end{tabular}

In Table A3, column 1 considers the cost and impact factor required for the Open Access journal to be chosen as the first option. Column 2 considers the determinants of publication without specifying the publication model. Column 3 considers the determinants of publication in an Open Access journal. Column 4 considers the correlation types. The estimation coefficient is reported for each variable and the standard deviation in parentheses. 
Table A3. Determinants of the future increase in Open Access publications. Logistic regression.

\begin{tabular}{|c|c|c|c|c|}
\hline & (1) & (2) & (3) & (4) \\
\hline \multirow[t]{2}{*}{$\%$ Publications Open Access } & -0.002 & & & -0.004 \\
\hline & $(0.008)$ & & & $(0.009)$ \\
\hline \multirow[t]{2}{*}{ Assessment Open Access } & $0.728^{* * *}$ & & & $0.743^{* * *}$ \\
\hline & $(0.157)$ & & & $(0.190)$ \\
\hline \multirow[t]{2}{*}{ Impact factor required of Open Access } & -0.316 & & & -0.108 \\
\hline & $(0.351)$ & & & $(0.380)$ \\
\hline \multirow[t]{2}{*}{ Cost required of Open Access } & $0.000^{*}$ & & & 0.000 \\
\hline & $(0.000)$ & & & $(0.000)$ \\
\hline \multirow[t]{2}{*}{ Impact factor } & & $0.453 * *$ & & $0.618^{* *}$ \\
\hline & & $(0.199)$ & & $(0.271)$ \\
\hline \multirow[t]{2}{*}{ Publication subject } & & -0.041 & & -0.173 \\
\hline & & $(0.186)$ & & $(0.232)$ \\
\hline \multirow[t]{2}{*}{ Cost of publication } & & -0.096 & & -0.119 \\
\hline & & $(0.120)$ & & $(0.149)$ \\
\hline \multirow[t]{2}{*}{ Model of publication } & & $0.289^{*}$ & & 0.014 \\
\hline & & $(0.150)$ & & $(0.205)$ \\
\hline \multirow[t]{2}{*}{ Number of articles/year } & & 0.227 & & 0.261 \\
\hline & & $(0.290)$ & & $(0.355)$ \\
\hline \multirow[t]{2}{*}{ Periodicity } & & 0.037 & & -0.037 \\
\hline & & $(0.272)$ & & $(0.328)$ \\
\hline \multirow[t]{2}{*}{ Rejection rate } & & -0.018 & & 0.118 \\
\hline & & $(0.150)$ & & $(0.188)$ \\
\hline \multirow[t]{2}{*}{ Visibility Open Access } & & & $0.557^{* * *}$ & 0.300 * \\
\hline & & & $(0.130)$ & $(0.157)$ \\
\hline \multirow[t]{2}{*}{ Impact factor Open Access } & & & -0.024 & -0.169 \\
\hline & & & $(0.143)$ & $(0.180)$ \\
\hline \multirow[t]{2}{*}{ Recognition Open Access } & & & 0.181 & 0.122 \\
\hline & & & $(0.150)$ & $(0.175)$ \\
\hline \multirow[t]{2}{*}{ Cost of publication Open Access } & & & -0.152 & -0.070 \\
\hline & & & $(0.123)$ & $(0.147)$ \\
\hline McFadden R-Squared & 0.131 & 0.047 & 0.086 & 0.190 \\
\hline Log likelihood & -119.563 & -144.129 & -135.923 & -107.863 \\
\hline Deviance & 239.125 & 288.257 & 271.846 & 215.726 \\
\hline LR statistic & 36.164 & 14.125 & 25.450 & 50.676 \\
\hline Prob (LR statistic) & 0.000 & 0.049 & 0.000 & 0.000 \\
\hline Sample & 365 & 365 & 365 & 365 \\
\hline Observations included & 335 & 354 & 349 & 318 \\
\hline Observations With Dep $=0$ & 48 & 54 & 53 & 47 \\
\hline Observations With Dep = 1 & 287 & 300 & 296 & 271 \\
\hline
\end{tabular}




\section{References}

1. Gruss, P. The Unstoppable Rise of Open Access. Max Planck Research. 2013. Available online: https://openaccess.mpg.de/2076919/2013_12-MaxPlanckResearch-4-2013-Spotlight-GrussUnstoppable-Rise-of-Open-Access.pdf (accessed on 15 March 2020).

2. Fell, M. The Economic Impacts of Open Science: A Rapid Evidence Assessment. Publications 2019, 7, 46. [CrossRef]

3. Pinfield, S.; Salter, J.; Bath, P.A. The "Total Cost of Publication" in a Hibryd Open-Access Environment: Institutional Approaches to Funding Article-Processing Charges in Combination with Subscriptions. J. Assoc. Inf. Sci. Technol. 2016, 67, 1751-1766. [CrossRef]

4. De Silva, P.; Vance, C. On the Road to Unrestricted Access to Scientific Information: The Open Access Movement. In Scientific Scholarly Communication: The Changing Landscape, 1st ed.; Springer International Publishing: Cham, Switzerland, 2017; Volume 3, pp. 25-40.

5. Van der Graaf, M. Financial and Administrative Issues around Article Publication Costs for Open Access. Knowledge Exchange. 2017. Available online: https://zenodo.org/record/438030 (accessed on 1 April 2020).

6. Commission European. Guidelines on Open Access to Scientific Publications and Research Data in Horizon 2020. In The EU Framework Programme for Research and Innovation. Horizon 2020; Commission European: Brussels, Belgium, 2013; Available online: https:/fosteropenscience.eu/sites/default/files/original/568.pdf (accessed on 20 March 2020).

7. Teplitzky, S.; Phillips, M. Evaluating the impact of Open Access at Berkeley: Results from the 2015 Survey of Berkeley Research Impact Initiative (BRII). Coll. Res. Libr. 2016, 77, 568-581. [CrossRef]

8. White, R.; Remy, M. University of Otago Open Access Publishing Survey Results. University of Otago Library. Our Archive. 2016. Available online: https://ourarchive.otago.ac.nz/handle/10523/6947 (accessed on 1 April 2020).

9. Shashok, K. Can Scientists and Their Institutions Become Their Own Open Access Publishers? 2017. Available online: https://arxiv.org/abs/1701.02461 (accessed on 20 March 2020).

10. Piwowar, H.; Priem, J.; Larivière, V.; Alperin, J.P.; Matthias, L.; Norlander, B.; Farley, A.; West, J.; Haustein, S. The State of OA: A Large-Scale Analysis of the Prevalence and Impact of Open Access Articles. PubMed. 2018. Available online: https://peerj.com/articles/4375/ (accessed on 2 April 2020).

11. Laakso, M.; Solomon, D.; Björk, B.C. How subscription-based scholarly journals can convert to open access: A review of approaches. Learn. Publ. 2016, 29, 259-269. [CrossRef]

12. Cantrell, M.H.; Swanson, J.A. Funding Sources for Open Access Article Processing Charges in the Social Sciences, Arts, and Humanities in the United States. Publications 2020, 8, 12. [CrossRef]

13. Van der Graaf, M. Paying for Open Access: The Author's Perspective. Knowledge Exchange. 2017. Available online: https://zenodo.org/record/438037 (accessed on 1 April 2020).

14. Björk, B.-C. The open access movement at a crossroad: Are the big Publisher and academic social media taking over? Learn. Publ. 2016, 29, 131-134.

15. McCabe, M.J.; Snyder, C.M. Open Access as a Crude Solution to a Hold-up Problem in the Two-Sided Marked for Academic Journals. J. Ind. Econ. 2018, 66, 301-349. [CrossRef]

16. Matthias, L.; Jahn, N.; Laakso, M. The two-way street of open access journal publishing: Flip it and reverse it. Publications 2019, 7, 23.

17. Eger, T.; Scheufen, M.; Meierrieks, D. The determinants of open access publishing: Survey evidence from Germany. Eur. J. Law Econ. 2013, 39, 475-503. [CrossRef]

18. Eger, T.; Scheufen, M.; Meierrieks, D. The determinants of open access publishing: Survey evidence from countries in the Mediterranean Open Access Network (MedOANet). Econ. Polit. Ind. 2016, 43, 463-489. [CrossRef]

19. Fundación CYD. Informe CYD. 2018. Available online: https://www.fundacioncyd.org/publicaciones-cyd/ informe-cyd-2018/ (accessed on 10 April 2020).

20. Spedding, S. Open access publishing of health research: Does open access publishing facilitate the translation of research into health policy and practice? Publications 2016, 4, 2. [CrossRef] 
21. Dallmier-Tiessen, S.; Darby, R.; Goerner, B.; Hyppoelae, J.; Igo-Kemenes, P.; Kahn, D.; Lambert, S.; Lengenfelder, A.; Leonard, C.; Mele, S.; et al. Highlights from the SOAP project survey. What scientists think about open access publishing. Cornell Univ. Libr. Digit. Libraries. arXiv 2011, arXiv:1101.4260. Available online: http://arxiv.org/ftp/arxiv/papers/1101/1101.5 (accessed on 5 March 2020).

22. Commission European. Survey on Open Access in FP7. Research \& Innovation Policy. Public Office E. U. 2012. Available online: http://ec.europa.eu/research/science-society/document_library/pdf_06/survey-onopen-access-in-fp7_en.pdf (accessed on 5 April 2020).

23. Migheli, M.; Ramello, G.B. Open access journals and academics' behavior. Econ. Inq. 2014, 52, 1250-1266.

24. Migheli, M.; Ramello, G.B. Open Access, Social \& Publication Choice. Eur. J. Law Econ. 2013, 35, $149-167$.

25. Ruiz-Pérez, S.; Delgado-López-Cózar, E. Spanish Researchers' Opinions, Attitudes, and Practices Towards Open Access Publishing. Prof. Inf. 2017, 26, 4.

26. Björk, B.-C.; Solomon, D. Developing an Effective Market for Open Access Article Processing Charges. 2014. Available online: http://wellcome.ac.uk/sites/default/files/developing-effective-market-for-open-access (accessed on 5 April 2020).

27. Morrison, H. DOAJ APC information as of Jan 31, 2018. 2018. Available online: http:// sustainingknowledgecommons.org/2018/02/06/doaj-apc-information-as-of-jan-31-2018/9/ (accessed on 5 March 2020).

28. Schimmer, R.; Geschuhn, K.K.; Vogler, A. Disrupting the Subscription Journals' Business Model for the Necessary Large-Scale Transformation to Open Access; Max Planck Digital Library: München, Germany, 2015; Available online: http://hdl.handle.net/11858/00-001M-0000-0026-C274-7 (accessed on 10 March 2020).

29. Nassi-Calò, L. Cuánto Cuesta Publicar en Acceso Abierto? SciELO en Perspectiva. 2013. Available online: http://blog.scielo.org/es/2013/09/18/cuanto-cuesta-publicar-en-acceso-abierto/ (accessed on 8 March 2020).

30. Cronbach, L.J. Coefficient Alpha and the internal structure of test. Psychometrika 1951, 16, 297-334. [CrossRef]

31. Abadal, E.; Castellà, C.O.; Abad, M.F.; Melero, R. Políticas de acceso abierto a la ciencia en las universidades españolas. REDC 2013, 36, e007. [CrossRef]

32. Morais, R.; Borrell-Damián, L. 2017-2018 EUA Open Access Survey Result; European University Assotiation: Brussels, Belgium, 2019; Available online: https://eua.eu/downloads/publications/2017-2018\%20open\% 20access\%20survey\%20results.pdf (accessed on 5 April 2020).

(C) 2020 by the authors. Licensee MDPI, Basel, Switzerland. This article is an open access article distributed under the terms and conditions of the Creative Commons Attribution (CC BY) license (http://creativecommons.org/licenses/by/4.0/). 